A aquisição de determinado material pode estar conforme a legislação que a disciplina:

- recurso orçamentário;

- modalidade de licitação adequada: prido;

- prazo de fornecimento cum-

- pagamento na data certa.

Suponhamos, entretanto, que esse material adquirido, com todo aquele "colorido," seja:

- um condicionador de ar que ficou no almoxarifado 2 anos; ou

- um tapete persa, que foi colocado no gabinete da Secretária do Diretor.

Veja-se que, quanto à legalidade, não há restrições. As normas legais foram obedecidas. Havia verba, houve licitação etc., mas tais despesas atendiam a alguma necessidade, no momento de sua realização? Claro que não. No primeiro caso, deuse o que chamamos, vulgarmente, de aproveitamento do recurso orçamentário para não cancelar saldos. No segundo caso, foi mero exibicionismo pessoal do gestor.

Nenhuma dessas duas despesas tinha foros de legitimidade. $\mathrm{O}$ ato do ordenador não foi legítimo como ação, no sentido de despesa pública propriamente dita.

Se a necessidade pública não comanda a ação, a despesa torna-se desnecessária, a exemplo das estocagens absurdas de material, abarrotando os almoxarifados e fazendo crer que a aquisição contenha outras intençōes ou benefícios pessoais.

E nem se venha argumentar com uma série de despesas que existem, tais como cafezinhos, higiene pessoal, as próprias despesas de representação. É preciso que se entenda que a sociedade é organizada em no. me do povo. Ele, povo, precisa de seus organismos e de suas instituiç̃es, mas as despesas de manuten. ção e funcionamento hão que se limitar às estritas necessidades, com moderação e sem extravagâncias.

Concluimos, pois, que:

a) a legalidade da despesa pública adquire-se com a previsão orçamentária e o cumprimento das formalidades legais estabelecidas para sua realização;

b) a legitimidade caracteriza-se quando atender a uma necessidade pública da comunidade e o seu interesse determinar, além de ser realizada pela autoridade competente.

\section{A questão do docente no ensino superior federal}

\author{
(*) Paulo Vieira da Silva
}

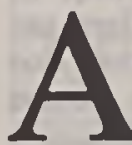

pesar de quase meio século de tentativas objetivas no sentido de conceitualizar e definir rumos para a institucionalização de uma política de mérito no serviço público, o fato é que até o presente momento muitas questōes ainda estão por ser resolvidas. Tal ocorre por um sem-número de razões que encontram raizes na própria estrutura de nossa sociedade.

Entre os pontos que precisam de esforço especial dos estudiosos, ressaltam aqueles que se referem ao mero conceito de carreira no serviço público. A bibliografia especializada em administração de pessoal ou de recursos humanos, trata de maneira aligeirada esse assunto. Por outro lado, a legislação que se refere ao ordenamento juridico dos servidores públicos não se tem comprometido em encontrar uma definição apresentável do que seja uma carreira. E a leitura atenta tanto de uma coisa como a de outra deixa uma forte impressão de que, em termos conceituais, tem predominado uma visåo faiolista que se esgota no mero esforço de definir o que é cargo público e quais as classes ou séries de classes em que eles se situam. Avançando um pouco além, procura-se explicar que a divisão de tarefas para cada um deles tem como referencial os niveis de complexidade e de responsabilidade previamente especificados.

Parece que o momento sugestivo para o aprofundamento desse assunto é o que se vive em termos de tentativas de elaboração de um novo

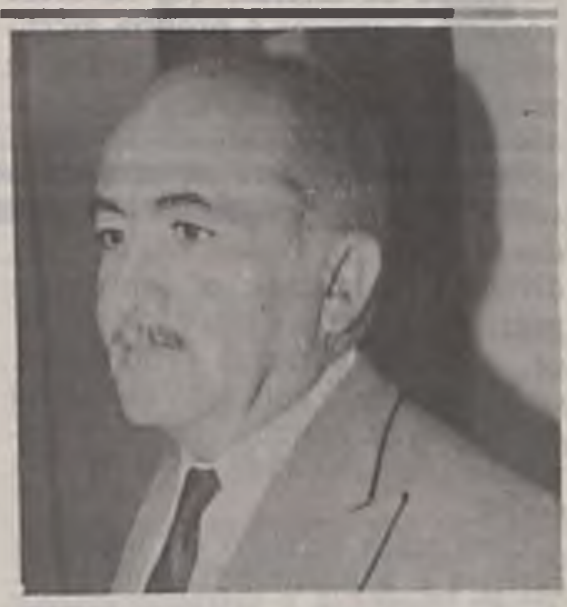

estatuto para os servidores públicos civis da União, e o da definição de mecanismos operacionais para o novo plano de cargos e salários para o pessoal docente de nivel superior das instituições federais, autárquicas ou fundacionais.

O propósito deste trabalho é o de trazer à discussão a questão da carreira, naquilo que ela tem de conceitualmente especifico, quando considerada nas entidades de ensino superior que agora contam com o referencial de um plano de cargos e salários, apresentando, ao final, algumas sugestōes à consideração dos setores interessados. O pressuposto é o de que a discussão do tema, para atender aos interesses do magistério superior, poderá também contribuir para o melhor entendimento do sentido de carreira no âmbito de interesse do funcionalismo público em geral.

(") Professor do Departamento de Administração da UnB e assessor legislativo da Cámara dos Deputados; mestre em Administraçăo Pública e Doutor (PhD) em Educação Superior pela Universidade do Sul da Califórnia 


\section{Carreira docente}

As organizaçōes mais bemsucedidas na estrutura social brasileira são exatamente aquelas que institucionalizaram uma carreira para seus efetivos. Entre elas, pode-se citar as três forças armadas, o corpo diplomático e o corpo de bombeiros. Há exemplos de outras experiências nesse sentido, como é o caso do Banco do Brasil e mais recentemente dos Correios.

Uma carreira pressupõe uma seqüência harmônica de niveis de autoridade, responsabilidade e complexidade de tarefas, que favorece aos seus membros a própria ascensão funcional, pela satisfação de seus requisitos básicos. Faz-se ela acompanhar de um plano de remuneração, o qual deve ser atraente o suficiente para funcionar como um dos fatores de retenção dos indivíduos na instituição. Em outras palavras, a carreira tem caracteristica, natureza e regras próprias. A continuidade de aplicação escorreita das regras da carreira conduz à formação do chamado "esprit des corps".

Uma regra de ouro em qualquer carreira é a possibilidade de o individuo que nela entre galgar todos os seus niveis até o último. Nesse sentido, chegar ao pináculo da carreira $\dot{e}$ o objetivo das pessoas em qualquer quadro. De fato, a classe mais alta tem sido o aliciente por excelência para induzir à permanência nos quadros, levando o individuo it profissionalização c constante aprimoramento pessoal na esperança dc chegar até lá, afinal. Suprima-sc, de repente, a classe mais alta do fluxo ascendente e ter-se-á tudo, menos uma carreira.

Assim, a oportunidade de ascensão é fundamental para a organização progressista - no sentido de comprometida com o progresso de seu efetivo ou corpo de pessoal - e tambèm para a função de desenvolvimento dos recursos humanos nela engajados. À guisa de exemplo, o militar que chega a coronel não ficará dependendo de concurso público para chegar a general. E tampouco o conselheiro de primeira classe ficaria dependendo de concurso público para chegar a ministro na carreira diplomática.

Esses exemplos mostram que há sempre normas básicas que formam o ordenamento da carreira, de molde a preservá-la em suas caracteristicas e finalidades, normas que asseguram o preenchimento de vagas ocorridas nos niveis e classes superiores preponderantemente por elementos da própria carreira.

Os tratadistas apontam dois tipos de carreira: o fechado e o semifechado. No primeiro, não se admite a renovação dos efetivos a não ser pelo ingresso de novos membros nos postos iniciais da carreira, como é o caso da carreira diplomática, onde os cargos são apanágio daqueles que começaram nos primeiros niveis. No segundo caso, se pode invocar as forças armadas, que permitem um ingresso discreto de estranhos aos quadros, ém determinados postos

\begin{tabular}{|c|}
\hline As organizações mais \\
bem-sucedidas na \\
estrutura social do \\
Brasil são aquelas que \\
criaram uma carreira \\
para seus servidores. \\
Pode-se citar os \\
exemplos das forças \\
armadas, do Itamarati, \\
do Banco do Brasile \\
mais recentemente a \\
Empresa Brasileira de \\
Correios e Telégrafos, \\
de flagrante evolução.
\end{tabular}

que requerem formação profissional especifica, quando então fazem concurso público para médicos, dentislas, engenheiros e afins. Nestes casos, os mais bem-sucedidos ingressam na carreira em regime especial, como capitao, mas podem chegar a coronel.

Quanto ao corpo docente, não há como dcixar de ver o seu caráter multifacetado, onde, apesar da integração proporcionada pela moderna universidade, os seus membros se agrupam por especialidade, cobrindo vastas áreas do conhecimento humano. Tal circunstância empresta uma dinâmica loda especial ao corpo docente, onde há necessidade de expressiva renovação de efetivos, para se conseguir um constante crescimento do conhecimento humano. Não se infira dai, no entanto, que o melhor seria deixar as suas classes em aberto, acessiveis a qualquer cidadão, a qualquer tempo, por concurso, pois então não haveria carreira. A todo instante aqueles que ingressaram na classe inicial por concurso estariam correndo o risco de ser alijados do contexto, bastando para isso que fossem mal-sucedidos numa prova pública para acesso à classe superior. Perderiam seu cargo e seus anos de dedicação à atividade docente.

Por isso mesmo, diante da necessidade de renovação de efetivos, para propiciar a injeção de "sangue novo" nos quadros, a boa norma de administração de recursos humanos recomenda que o ingresso de pessoas de fora da carreira se faça em proporcões tais que aquela regra de ouro não seja ferida de morte, ou seja, que se adote um percentual de vagas a serem preenchidas por concurso. De um modo geral se prefere estabelecer que um terco das vagas das classes intermediárias e final seja preenchido, mediante a satisfação de regras especificas, sob a forma de concurso público. Mantém-se, por outro lado, a regra do ingresso na classe inferior apenas mediante competição pública.

$\mathrm{O}$ concurso público - critério exclusivo para ingresso na classe de assistente e parcial para ingresso nas classes de adjunto e titular - consulta muito mais uma sadia politica voltada para a implementação do sistema do mérito do que a mera obediência ao que dispōe a Constituição Federal. A inteligência do que dispõe o art. 176 da Carta Magna é a de que este é especialização do artigo 97 , ambos relativos ao regime jurídico dos funcionários públicos civis da União, exclusivos dos quadros da administração direta e das autarquias.

Por outro lado, a própria estruturaça da carreira, em termos de nomenclatura e de conteúdo, ainda está sujeita a uma redefinição. Em vários paises, com experiência mais expressiva que a nossa no trato de assuntos acadêmicos e universitários, a categoria foi depurada em três classes - professor assistente, professor associado e professor - que bem poderiam ser lembradas para solução do nosso problema conceitual e de especificação de classe.

Inicialmente se preferiu, em nosso meio, a expressão "adjunto" para uma das classes e "titular" para a 
classe final (a figura do catedrático é anterior a essa conceituação e não está vinculada ao esforço mais recente de criação da carreira docen(e). No cntanto, ao termo adjunto se empresta, também, uma conotaçāo de assistente, auxiliar, ajudante, que $\dot{c}$, no caso, concorrente com a denominaçào professor assistente. Mas $\mathrm{cm}$ termos de conteúdo e de autonomia docente a categoria adjunto está muito mais presa e próxima à de titular c, por isso mesmo, deveria chamar-se professor associado. Esse termo, associado, tem uma conotação de ação participe, ativa e sem dependência objetiva.

\section{Sugestōes especificas}

No momento em que se estudam formas capazes de favorecer a instilucionalização da carreira docente no cnsino superior, é importante diante do quadro referencial supramencionado trazer à discussão dos setores interessados proposiçoes como as que se seguem:

a) entender promociào como o acesso do professor na escala hierár. quica, de uma classe para outra superior, compreendendo, simultaneamente, atribuiçāo de deveres e responsabilidades mais dificeis e complexas, bem como o respectivo aumento de remuneração;

b) entender progressão como o mero deslocamento horizontal em graus ou niveis, sem mudança dt atribuiçōes e responsabilidades, isto é, com mudança apenas de salário;

c) estabelecer as seguintes calegorias de professores do corpo docente: professores da carreira, professores visitantes e auxiliares de ensino;

d) estabelecer as seguintes classes para a carreira docente: professor tiiular, professor associado e professor assistente;

c) entender o professor-titular como aquele de notório saber, com qualificação pós-doutoral, na plenitude da sua capacidade e autonomia de ensino;

f) entender o professor associado como aquele com qualificação douloral, cuja autonomia e reconhecimento público ainda se encontram em desenvolvimento;

g) entender o professor-assistente como aquele com formação magistral, cuja qualificação docente encontra-se em franco desenvolvi-

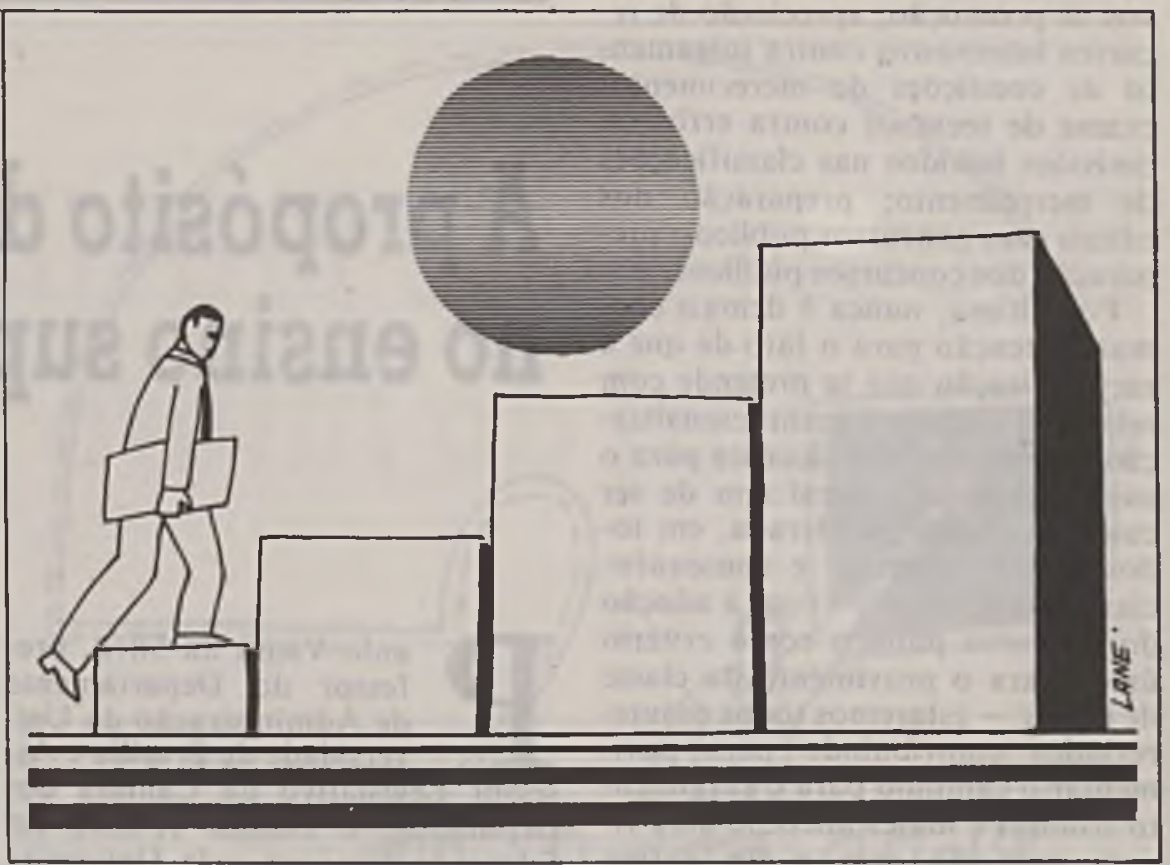

mento, responsabilizando-se temporariamente por disciplinas introdutórias ou assuntos docentes de pouca complexidade;

h) adotar o concurso público de provas e de titulos como única forma de ingresso na base da carreira, isto é, na classe de professorassistente;

i) adotar para o preenchimento de vagas nas classes de professorassociado e professor-titular o seguinte critério:

- dois terços, por merecimento, de professores da carreira;

- um terco, por concurso público de provas e títulos (aqui, por definição, qualquer um, da carreira ou não, pode concorrer, satisfeitas as regras básicas para ingresso nessas

Uma regra de ouro em qualquer carreira é abrir a possibilidade de o individuo galgar todos os seus níveis. Chegar ao último é motivação decisiva para fixaro servidor ou empregado ao órgão ou empresa em que exerce atividades. $E$ este é um momento adequado para pensar na adoção desses estímulos no serviço público. classes) e por notório saber;

j) admitir a existência de três a quatro niveis ou graus nas duas primeiras classes (assistente e associado) aos quais se aplicaria o instituto da progressão;

1) definir as regras que consubstanciam o merecimento, nas quais podem conviver a avaliação de desempenho, o concurso interno, a senioridade e o intersticio e outros modos de identificar a habilitaçào do professor à classe imediatamente superior;

m) entender as funçōes de auxiliar de ensino, para iniciação nas atividades docentes, como destinadas principalmente a mestrandos e excepcionalmente àqueles apenas graduados em curso superior. O contrato seria por tempo determinado, para induzir à habilitação para ingresso na carreira;

n) criar uma comissão de carreira, em cada entidade de ensino superior, mormente nas fundacionais, subordinada ao Conselho de Ensino e Pesquisa, ou equivalente, com as seguintes atribuiçōes e atividades, entre outras:

Padronização e uniformização de julgamentos de merecimento, eliminando excessos cometidos, com o propósito de permitir justas e equânimes classificaçōes; centralizar o processamento das promoçoes a serem realizadas; revisāo de avaliacőes de merecimento; elaboração das classificaçōes de merecimento; elaboração dos expedientes definiti- 
vos de promoção; apreciação de recursos interpostos contra julgamento de condições de merecimento; exame de recursos contra erros ou omissões havidos nas classificações de merecimento; preparação dos editais para concursos públicos; preparação dos concursos públicos.

Por último, nunca é demais chamar a atenção para o fato de que a racionalização que se pretende com relação à criação e institucionalização de uma carreira docente para o ensino superior federal tem de ser cuidadosamente ponderada, em todos os seus aspectos e conseqüências. Do contrário - com a adoção do concurso público como critério único para o provimento da classe de titular - estaremos todos os interessados contribuindo para pavimentar o caminho para o surgimento triunfal e majestático de uma figura parecida com a do antigo catedrático - o dono da cátedra com sua sebenta e tudo que ela tem de deletério, retrógrado e esterilizante no âmbito do ensino superior.

\section{Sugestōes para leitura:}

livros: Stahl, O. Glenn - Public Personnel Administration;

NY: Harpers \& Bros, 6: ed., 1965

Aquino, Cleber P. Administratiáo de Recursos Humanos.

SP: Atlas, 1979

Likert, Rensis A Organizatio Humana. SP: Allas, 1975

Jun, J. e Storm, W.B. Tomorrow's Organizations: challenges and strategies. USA: Foresman, 197.3

Fayol, Henri Administraciao Industrial e Gieral. SP: Atlas 1968

Berkley, (i. A Revolusia Administrativa. RJ: Lxpressato e Cultura, 1972

artigos: Randall, li.l). "Stimulate your Executives to Think Creatively" - Harvard Business Review, ñ. 4.1956

Mac(iregor, D. "An Uneasy Look to l'ersonnel Appraisal" Harvard Business Review, n³ 1957

Varela, J.A. "Whay Promotions Cause Trouble and How to Avoid II". Revista Personnel, nov./dez. 1964

leis: Dec. Lei n² 1.713, de $28 / 10 / 39$

Lei no 1.711 , de $28 / 10 / 52$

Lei n- 5.540 , de $28 / 11 / 68$

Lei n- 5.645 , de $10 / 12 / 70$

Dec-lei n: 200, de 25/2/67

Constituição I'ederal de 1967.
IDÉIAS

\section{A propósito do docente no ensino superior federal}

\author{
Gilberto Tristão(*)
}

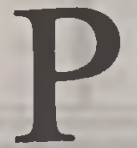

aulo Vieira da Silva, professor do Departamento de Administração da Universidade de Brasília e Assessor Legislativo da Câmara dos Deputados, é Doutor (Ph.D) em Educação Superior pela University of Southern California. Em seu artigo, traz à discussåo "a questão da carreira naquilo que ela tem de conceilualmente especifico quando considerada nas entidades de ensino superior que agora contam com o referencial de um plano de cargos e salários". Entretanto, preocupa-se em enfocar o assunto sob bases mais amplas, quando afirma que a discussito do tema "poderá também contribuir para o melhor entendimento do sentido de carreira no âmbito de interesse do funcionalismo publico cm geral".

IEssa sugestão, até mesmo pela funçio que estou exercendo no momeilto. Chefe de unidade de ensino de graduaçáo e pós-graduação, levou-me a refletir sobre um aspecto especifico da carreira: a sua contribuicia para a produtividade do servidor.

As Instiluições de Ensino Superior (IES) estĩo mais voltadas para o cusino do que para a pesquisa, a extensão e a administração. Esse fato faz com que até o lempo do professor seja basicamente alocado a disci-

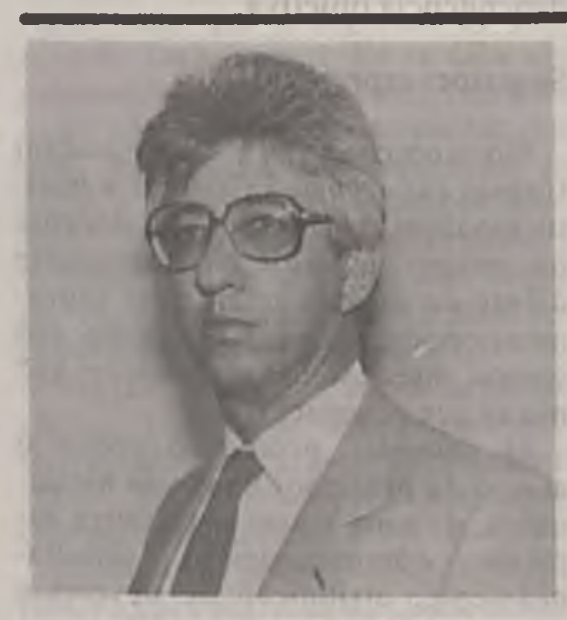

plinas, devendo o Chefe do Departamento preocupar-se com o cumprimento da carga horária estabelecida nos contratos de trabalho: no regime anterior, professores $T P-12$, TP-24 e DE. Atualmente, professor de 20 horas e DE.

O sistema universitário não evoluiu para estabelecer parâmetros de comprometimento dos docentes com as demais atividades. Ou seja:

*quantas pesquisas por ano teria que realizar o professor em regime de 20 horas e o em DE;

*Quantos artigos por ano teria que publicar o professor em regime de 20 horas e o em DE:

*quantos livros por triênio teria que

\begin{tabular}{|c|c|c|c|c|}
\hline$\overbrace{\text { NIVEL }}^{\text {PR: DUTIVI }}$ & PESQUISAS & ARTIGOS & LIVROS & $\begin{array}{l}\text { NOTORIO SABER } \\
\text { POR NIVEL }\end{array}$ \\
\hline $\begin{array}{l}\text { Ass:ster } \\
\text { Adj:nto }\end{array}$ & $x+\Delta x=x_{1}$ & $\stackrel{Y}{Y}+\Delta Y=I_{1}$ & $z+\Delta z=z_{i}$ & $\begin{array}{l}N=X_{1}+Y+Z \\
N_{1}=X_{1}+Y_{1}+Z 1\end{array}$ \\
\hline Tit:lar & $x_{1}+\Delta x=x_{2}$ & $y_{j}+\Delta y=y_{2}$ & $z j+\Delta z=z_{2}$ & $N_{2}=x_{2}+Y_{2}+z_{2}$ \\
\hline
\end{tabular}

- Chefe do Departamento de Administração da Universidade de Brasilia. UnB 